\title{
Rural/ Urban differences in health services deficits among U.S. adults with arthritis: A population- based study
}

\author{
May Nawal Lutfiyya ${ }^{1}$, J oel Emery McCullough ${ }^{2}$, Daniel M Saman ${ }^{1}$, Andrine Lemieux ${ }^{1}$, Sara \\ Hendrickson ${ }^{1}$, Cynthia A McGrath ${ }^{3}$, I rina V Haller ${ }^{1}$, Martin Stephen Lipsky ${ }^{4}$
}

1. Essentia Institute of Rural Health, Division of Research, Duluth, USA. 2. Spokane Regional Health District, Spokane, USA. 3. Saint Anthony College of Nursing, OSF Healthcare System, Rockford, USA. 4. Department of Community and Family Medicine, University of Illinois-Chicago College of Medicine at Rockford, Rockford, USA

Correspondence: May Nawal Lutfiyya. Address: Essentia Institute of Rural Health, Division of Research, Duluth, MN 55805, USA. Email: mlutfiyya@eirh.org.

Received: January 6, 2013

DOI : $10.5430 /$ jnep.v3n11p43
Accepted: February 25, $2013 \quad$ Online Published: April 15, 2013

URL: http://dx.doi.org/10.5430/jnep.v3n11p43

\section{Abstract}

Introduction: More than $21 \%$ of adults in the United States (U.S.) have self-reported physician diagnosed arthritis with the prevalence increasing to $70 \%$ for adults aged 75 years and older. Despite significant disease burden of arthritis, little research has been conducted to examine health service deficits experienced by U.S. adults with this disease. Since U.S. rural residents experience more disease and greater health and health care disparities than urban residents, this study sought to ascertain the prevalence of health service deficits in U.S. adults with arthritis and to explore whether rural residents experienced greater deficits than urban residents.

Methods: Multivariate techniques were performed on 2011 Behavioral Risk Factor Surveillance System data to determine if there were differences in the prevalence of health service deficits in rural versus urban adults with arthritis and if rural residency was an independent risk factor for health service deficits after controlling for socioeconomic status and race/ ethnicity. The population of interest was U.S. adults who self-reported having arthritis diagnosed by a health care provider.

Results: Bivariate analysis revealed and logistic regression confirmed that among U.S. adults $>45$ years of age, rural residency was a predictor for a higher prevalence of arthritis as well as for health service deficits among those with arthritis. Overall about 1 in 3 individuals $>45$ years of age suffering from arthritis experienced a health deficit. The two most common health service deficits were not having a routine medical checkup within the last 12 months and deferring health care because of cost. Rural residency emerged as an independent risk factor for health service deficits after controlling for socioeconomic status and race/ethnicity.

Conclusions: Many individuals with arthritis experience a health service deficit and rural residents are at greater risk when compared to their urban counterparts. Given the burden of disease from arthritis the results suggest that there is considerable potential for improving services and perhaps improving outcomes for individuals with arthritis. The finding that the most common health service deficits were delaying care because of cost and not having seen a provider within the last 12 months suggests that finances rather than simply the availability of services is a key factor. 


\section{Key words}

Arthritis, Health service deficits, Rural health disparities

\section{Introduction}

Arthritis is a condition involving pain or dysfunction of one or more joints. While there are over 100 different types or forms of arthritis, osteoarthritis (OA) is the most common ${ }^{[1]}$. Many note that arthritis is a large and growing public health problem due, in part, to an aging population in the U.S. In a recent analysis of data from the National Health Interview Survey (NHIS) more than $21 \%$ of U.S. adults (46.4 million persons) had self-reported physician-diagnosed arthritis ${ }^{[2]}$. For people older than 75 years, the prevalence estimate for OA rises to between $70 \%-90 \%{ }^{[1]}$.

While the etiology of $\mathrm{OA}$ is multifactorial, the condition is a result of the gradual degeneration of articular cartilage that normally cushions the bones in a joint. When healthy, cartilage replaces itself. This replacement process is disrupted when OA occurs. The damaged cartilage can lead to boney outgrowth and joint damage as the cushion of cartilage disappears. $\mathrm{OA}$ is most commonly found in joints that bear weight, such as knees, hips, spine as well as hands ${ }^{[1,3]}$.

OA can cause substantial disability among older adults ${ }^{[1]}$. With the exception of cardiovascular disease, the risk of disability for older adults attributable to knee OA alone is greater than any other medical disorder ${ }^{[4]}$. Almost $80 \%$ of patients with OA have some limitations in movement and about one in four report some limitations in their activities ${ }^{[5,6]}$. Multiple risk factors are associated with OA including: heredity, age, being female, trauma, and low bone density ${ }^{[7]}$. In addition, obesity is considered a major risk factor for both the development and progression of $\mathrm{OA}^{[8]}$.

Despite its significant disease burden, health service deficits experienced by U.S. adults with arthritis have not been examined. A health service deficit is an evolving analytic concept for use in health service-related research ${ }^{[9]}$ that facilitates the examination of how a group or population uses of health services relevant to their condition. Four common factors that contribute to a health service deficit are: lacking health insurance, lacking a healthcare provider, deferring medical care because of cost, and failure to obtain a routine medical exam, all within the last 12 months ${ }^{[9]}$.

There is also an increasing recognition that location matters, that geographic locale may affect individuals' risk for health service deficits and that where a person lives can impact their health and health care ${ }^{[10,11]}$. In particular, many health and health care disparities across the age continuum for rural populations have been documented. In addition to being a medically underserved population, U.S. rural residents experience more disease and greater health and health care disparities than urban residents ${ }^{[12,13]}$. Specifically, compared to the urban population, rural populations have higher prevalences of uninsured adults, adults with chronic conditions such as diabetes and cardiovascular disease, adolescent and adult smoking, and below-guideline consumption of fruits and vegetables ${ }^{[12-19]}$. Other important disparities in social determinants of health have also been detected for rural U.S. residents including higher poverty levels and lower levels of attained education. Finally, rural communities bear a heavier mental health burden than urban communities and research has repeatedly shown that poorly treated depression and other mental health conditions contribute to a higher burden of subjective pain and disability ${ }^{[20-23]}$. A recent publication points out that rurality itself should be considered a fundamental or root cause of poor health ${ }^{[11]}$.

The purpose of this study was to ascertain the prevalence of health service deficits in U.S. adults with a self-reported health care provider diagnosis of arthritis and to explore whether rural residents experienced greater health service deficits than urban residents. By analyzing data from the Behavioral Risk Factor Surveillance System (BRFSS), a large national surveillance database, this study sought to fill in an important epidemiological gap regarding arthritis and health service deficits. Furthermore, examining data collected by a large national surveillance system such as BRFSS allows for an analysis that incorporates an array of covariates not available from clinically-based data alone. Identifying potential gaps 
in service for chronic conditions such as arthritis is useful for developing targeted strategies for those in need of care and not receiving it.

\section{Methods}

This study analyzed 2011 BRFSS data to examine health service deficits as an important dimension of arthritis epidemiology and to determine if there were differences in the prevalence of health service deficits in rural versus urban adults with arthritis. The study used 2011 BRFSS data because they were the most recently available BRFSS data.

BRFSS is the largest surveillance system in the world ${ }^{[24]}$. BRFSS data are collected using a random-digit telephone survey targeting adults 18 through 99 years of age. These data are collected under the aegis of the Centers for Disease Control and Prevention (CDC) in collaboration with all US states and most U.S. territories. Once collected, BRFSS data are weighted by state or territory to represent the non-institutionalized U.S. adult population. BRFSS data are cross-sectional and are focused on health risk factors and behaviors as well as chronic diseases. A detailed description of the survey design and sampling measures can be found elsewhere ${ }^{[24]}$.

For this analysis the population of interest was U.S. adults who answered yes to the question: Has a doctor, nurse, or other health professional ever told you that you had arthritis. All analyses were performed on weighted data as is recommended by the CDC. The weighting, calculated by the CDC, uses the most recently available census data to provide a stratified representation of the nation's non-institutionalized population.

In the analyses presented here a number of variables were either re-coded or computed. All re-coding entailed collapsing categories and removing the responses don't know and refused. Computed variables included health service deficits, socioeconomic status (SES), and race/ethnicity.

The dependent variable, health service deficits, was constructed from four variables included in the BRFSS databaselack of health insurance, not having a healthcare provider, deferring medical care because of cost and having had no routine medical exam within the past 12 months. These variables were chosen because they all impact how individuals interact and access the health care system. A health service deficit was defined as having at least one of these present.

SES, also a computed covariate, was one of the primary independent variables in this research. According to the World Health Organization (WHO), SES is one of the strongest determinants of health ${ }^{[25]}$. While SES is a commonly used term in analyses across disciplines (e.g., sociology, social epidemiology, social psychology), many have noted that no general consensus exists about how to either define or measure the construct ${ }^{[26-28]}$. Typically SES refers to a combination of household income and other social measures such as attained educational level indexed into a single variable ${ }^{[26]}$. The most important purpose of SES is to provide a means for comparing relative position with regard to others. Almost always, SES is computed as a three-level variable (i.e., low, middle and high) ${ }^{[28]}$. Others have noted that various measures of SES are not interchangeable and that each one assesses a different aspect of SES that reflects the intent and approach of the investigator ${ }^{[28]}$. In the current study, SES is comprised of two categorical variables: education and income. In keeping with convention, data categories from each of these individual variables were coded as one of low, mid-range or high and numbered 1, 2 or 3 respectively. The variables with numbered factors or categories were then added together to create the composite variable of SES. Categories for education included: low $=$ less than high school (coded as 1 ), mid-range $=$ high school graduate (coded as 2), and high $=$ at least some college (coded as 3). Categories for income were, low $=<\$ 25,000$ (coded as 1), mid-range $=\$ 25,000-<\$ 50,000($ coded as 2$)$, and high $=>\$ 50,000($ coded as 3$)$. The possible range for the SES variable was 2-6 points. Subsequently, these points were indexed in the following manner: low $=2-3$ points, mid-range $=4-5$ points and high $=6$ points. These cut-points were purposive. For the lowest range of the index, 2 points were the floor (smallest possible point assignment), for the mid-range of the index, 4 points was the floor and for the high 
range of the index, 6 points was the floor. Any points below the floor for the mid-range were assigned to the lowest index category just as any points below the floor for the highest index category were assigned to the mid-range index category.

The race/ethnicity variable was calculated from participant responses to two separate survey questions — one regarding race and the other regarding Latino/Hispanic ethnicity. All race/ethnicity categories were computed as mutually exclusive entities: Caucasian, African American, Hispanic and Other/multiracial. All respondents who chose white as their racial classification were coded as Caucasian; those who chose black as their racial classification were coded as African American. Respondents who chose other racial classifications including more than one race were coded as Other/ multiracial. If a respondent identified themself as Hispanic or Latino they were classified by that ethnic category regardless of any additional racial classification.

This study used the Metropolitan Statistical Area (MSA) variable included in BRFSS to define geographic locale as either rural or urban. MSA was re-coded by collapsing categories into those of rural and urban. Rural residents were defined as persons living either within an MSA that had no city center or outside an MSA. Urban residents included all respondents living in a city center of an MSA, outside the city center of an MSA but inside the county containing the city center, or inside a suburban county of the MSA.

Bivariate and multivariate analyses were performed on the 2011 BRFSS data. To describe the U.S. adult population with arthritis a contingency table analysis was performed with the study variables by geographic locale using a chi square as the test statistic. Since this descriptive analysis yielded results similar to other studies ${ }^{[5,6]}$ indicating a higher prevalence for arthritis in U.S. adults $>45$ years of age all subsequent analyses were performed on this subpopulation. Bivariate analysis was performed to examine the relationship between health service deficits and SES by race/ethnicity and geographic locale. Multivariate logistic regression analysis was performed to examine health service deficits experienced mutually adjusting for SES, race/ethnicity and geographic locale.

Additionally, we examined the distribution of health service deficits by U.S. state. ArcMap version 10.0 (ESRI, Redlands, CA) was used to map the prevalence of health service deficits for U.S. rural adults $>45$ years of age with arthritis for each U.S. state's rural population. The prevalence of health service deficits for the relevant population was displayed by equal tertile percentages in order to visually identify the states with the lowest, middle, and highest prevalence range.

Statistical Package for Social Scientists (SPSS, IBM, Chicago, IL, version 19.0) was used to complete all statistical analyses. Alpha was set at $p<0.05$ for all statistical analyses. No Institutional Review Board (IRB) approval was required since this was a data only study.

\section{Results}

Table 1 displays the characteristics of adults $\geq 18$ years of age with arthritis by geographic locale (rural vs. urban). All differences assessed by a chi square test were significant at $p<0.05$ (not shown on table). For both geographic locales, high proportions of adults with arthritis were unemployed and not seeking employment. Rural adults, however, had a higher proportion in this category than urban adults. A higher proportion of rural adults self-reported their health as fair to poor compared to urban adults. Additionally, a significantly higher proportion of rural adults rated their physical health as not good 14 or more days in the past 30 days compared to urban adults. Moreover, a higher proportion of rural adults reported being inactive, as well as having activity limitations.

A greater proportion of rural adults were classified as lower SES, as not having health insurance, and as having deferred medical care because of cost. Furthermore, a higher proportion of rural adults had at least one health service deficit. For both geographic locales, adults $\geq 45$ years of age constituted the majority of arthritis cases. 
Table 1. Characteristics of U.S.

\begin{tabular}{|c|c|c|c|}
\hline Variables & Factors & $\begin{array}{l}\text { Urban (\%) } \\
n=38,419,558 *\end{array}$ & $\begin{array}{l}\text { Rural (\%) } \\
\mathrm{n}=11,259,237 *\end{array}$ \\
\hline \multirow{2}{*}{ Gender } & Male & 38.6 & 41.1 \\
\hline & Female & 61.4 & 58.9 \\
\hline \multirow{2}{*}{ Marital Status } & Married or Living with a Partner & 57.4 & 60.9 \\
\hline & Not Married or Partnered & 42.6 & 39.1 \\
\hline \multirow{4}{*}{ Race and Ethnicity } & Caucasian & 74.8 & 86.2 \\
\hline & African American & 10.9 & 6.1 \\
\hline & Hispanic & 8.7 & 3.5 \\
\hline & Other/Multiracial & 5.5 & 4.2 \\
\hline \multirow{2}{*}{ Age } & 44 Years And Younger & 12.8 & 13.6 \\
\hline & 45 Years And Older & 87.2 & 86.4 \\
\hline \multirow{3}{*}{ Employment Status } & Employed for Wages & 35.1 & 31.7 \\
\hline & Unemployed Seeking Employment & 6.4 & 5.5 \\
\hline & Not Employed/Not Seeking Employment & 58.5 & 62.8 \\
\hline \multirow{2}{*}{ Health Status } & Good to Excellent & 66.3 & 61.6 \\
\hline & Fair to Poor & 33.7 & 38.4 \\
\hline Days Physical Health & Fewer Than 14 Days & 73.8 & 71.3 \\
\hline Not Good & 14 Or More Days & 26.2 & 28.7 \\
\hline \multirow{2}{*}{ Physical Activity } & Active & 48.3 & 42.8 \\
\hline & Inactive & 51.7 & 57.2 \\
\hline \multirow{2}{*}{$\begin{array}{l}\text { Physical Activity } \\
\text { Limited }\end{array}$} & Not Limited & 49.8 & 47.5 \\
\hline & Limited & 50.2 & 52.5 \\
\hline \multirow{3}{*}{ Socioeconomic Status } & Lower SES & 44.7 & 55.6 \\
\hline & Middle SES & 43.4 & 38.8 \\
\hline & High SES & 11.9 & 5.7 \\
\hline \multirow{2}{*}{ Health Insurance Status } & Do Not Have Health Insurance & 8.8 & 10.9 \\
\hline & Have Health Insurance & 91.2 & 89.1 \\
\hline \multirow{2}{*}{ Healthcare Provider } & Do Not Have Healthcare Provider & 7.4 & 8.1 \\
\hline & Have Healthcare Provider & 92.6 & 91.9 \\
\hline Deferment of Medical & Did not Defer Care Because of Cost & 84.6 & 82.8 \\
\hline Care Because of Cost & Deferred Care Because of Cost & 15.4 & 17.2 \\
\hline \multirow{2}{*}{$\begin{array}{l}\text { Last Routine Medical } \\
\text { Checkup }\end{array}$} & Within Past 12 Months & 79.5 & 77.7 \\
\hline & Longer than 12 Months Ago & 20.5 & 22.3 \\
\hline \multirow{2}{*}{ Health Service Deficits } & No Health Service Deficits & 66.1 & 62.5 \\
\hline & At Least One Health Service Deficit & 33.9 & 37.5 \\
\hline
\end{tabular}

Note. Adults $>18$ Years of Age with Arthritis by Geographic Locale (Urban/Rural), 2011 BRFSS (n=49,678,795*)

* weighted $n$

An examination of the data to ascertain arthritis prevalence by geographic locale yielded that rural adults $\geq 45$ years of age had greater odds of having arthritis than urban adults $(\mathrm{OR}=1.150,95 \% \mathrm{CI}=1.149-1.151$, weighted $\mathrm{n}=106,778,771)$. Additionally, an analysis of the data to ascertain if there were differences in the prevalence of health service deficits for this population revealed that rural adults $\geq 45$ years of age with arthritis had greater odds of having at least one health service deficit $(\mathrm{OR}=1.116,95 \% \mathrm{CI}=1.115-1.117$, weighted $\mathrm{n}=42,905,402)$.

Table 2 displays the results of an analysis of geographic locale and race/ethnicity by SES for U.S. adults $\geq 45$ years of age with arthritis and at least one health service deficit. There is a clear gradient across SES categories among rural adults as well as for African American and Hispanic adults. For example, a greater percentage of rural residents were in the lower SES category than their urban counterparts (55.9\% vs. $45.0 \%)$, while the rate of high SES residents in rural locales was 
half that of urban locales (5.8\% vs. 11.6\%). Further, African Americans and Hispanic adults accounted for a higher proportion of respondents with the lower SES than Caucasians (66.8\% and $75.1 \%$, respectively).

Table 2. U.S. Adults $>45$ Years of Age with Arthritis and at Least One Health Service Deficit-Geographic Locale and Race and Ethnicity by Socioeconomic Status. 2011 BRFSS Data

\begin{tabular}{lllll}
\hline \multirow{2}{*}{ Variable } & Factors & Socioeconomic Status & & High SES (\%) \\
\cline { 3 - 5 } Geographic Locale & Lrban & 45.0 & 43.3 & 11.6 \\
& Rural & 55.9 & 38.3 & 5.8 \\
& Caucasian & 44.3 & 44.9 & 10.8 \\
& African American & 66.8 & 28.7 & 4.5 \\
Race And Ethnicity & Hispanic & 75.1 & 21.4 & 3.5 \\
& Other/Multiracial & 45.7 & 38.7 & 15.6 \\
\hline
\end{tabular}

Table 3 displays the results of a logistic regression analysis performed using at least one health service deficit as the dependent variable for U.S. adults $\geq 45$ years of age with arthritis. SES, geographic locale and race/ethnicity were the covariates included into the model. This analysis yielded that in comparison to high SES individuals, those who were low and/or middle SES had greater odds of having at least one health service deficit. All categories of race/ethnicity had greater odds of having at least one health service deficit when compared to Caucasians. Rural adults $\geq 45$ years of age with arthritis also had greater odds of having at least one health service deficit than similar urban adults.

Table 3. Logistic Regression of Having At Least One Health Service Deficit (HSD) Among U.S. Adults > 45 Years of Age with Arthritis by Race/Ethnicity, Socioeconomic Status and Geographic Locale. 2011 BRFSS Data

\begin{tabular}{lll}
\hline Independent Variable and Factors & & $\begin{array}{l}\text { Mutually Adjusted Odds Ratio for at Least One } \\
\text { HSD (95\% CI) }\end{array}$ \\
\hline \multirow{2}{*}{ Socioeconomic Status } & Low SES & $2.070(2.065,2.076)$ \\
& Middle SES & $1.275(1.272,1.279)$ \\
& High SES & * $^{*}$ \\
& African American & $1.136(1.133,1.138)$ \\
Race and Ethnicity & Hispanic & $1.618(1.614,1.622)$ \\
& Other/Multiracial & $1.304(1.300,1.308)$ \\
Geographic Locale & Caucasian & * $^{*}$ \\
& Rural & $1.139(1.138,1.141)$ \\
\hline
\end{tabular}

* Reference category

Table 4 displays the percent of US rural adults with arthritis who had at least one health service deficit by state. The percentages ranged from a low of $24.22 \%$ in Delaware to a high of $54.96 \%$ in Alaska. In four states, Alaska, Montana, Nevada and Wyoming, $50 \%$ or greater of the population of interest had at least one health service deficit. In 21 states $40 \%$ or greater of the population of interest had at least one health service deficit. Figure 1 geographically displays equal tertile health service deficit percent ranges by state for U.S. adults $\geq 45$ years with a self-reported health care provider arthritis diagnosis. Three administrative units (the District of Columbia, Rhode Island and New Jersey) had no data for rural vs. urban comparison.

\section{Discussion}

Descriptive analysis revealed that for U.S. adults $>45$ years of age with arthritis a number of disparities exist. For example, U.S. adults $>45$ years of age with arthritis and at least one health service deficit have higher proportions of low 
SES individuals. The multivariate analysis revealed that, similar to rural residency, low and middle SES and nonCaucasianrace/ethnicity (African American, Hispanic, and other/Multiracial) were predictors for health service deficits for U.S. adults $>45$ years of age with arthritis.

Table 4. Percent of U.S. Rural Adults $>45$ Years with Arthritis with at least one Health Service Deficit by State. 2011 BRFSS Data (weighted $n=4,224,806$ )

\begin{tabular}{|c|c|}
\hline State* & Rural Health Service Deficit (\%) \\
\hline Alabama & 35.59 \\
\hline Alaska & 54.96 \\
\hline Arizona & 43.46 \\
\hline Arkansas & 40.93 \\
\hline California & 41.06 \\
\hline Colorado & 44.32 \\
\hline Connecticut & 40.83 \\
\hline Delaware & 24.22 \\
\hline Florida & 37.71 \\
\hline Georgia & 41.95 \\
\hline Hawaii & 38.85 \\
\hline Idaho & 43.27 \\
\hline Illinois & 38.76 \\
\hline Indiana & 39.13 \\
\hline Iowa & 28.03 \\
\hline Kansas & 33.49 \\
\hline Kentucky & 39.23 \\
\hline Louisiana & 37.63 \\
\hline Maine & 31.93 \\
\hline Maryland & 26.55 \\
\hline Massachusetts & 27.35 \\
\hline Michigan & 34.79 \\
\hline Minnesota & 33.72 \\
\hline Mississippi & 41.33 \\
\hline Missouri & 41.69 \\
\hline Montana & 50.00 \\
\hline Nebraska & 38.12 \\
\hline Nevada & 54.22 \\
\hline New Hampshire & 28.45 \\
\hline New Mexico & 47.33 \\
\hline New York & 30.19 \\
\hline North Carolina & 33.70 \\
\hline North Dakota & 37.10 \\
\hline Ohio & 33.89 \\
\hline Oklahoma & 40.82 \\
\hline Oregon & 41.31 \\
\hline Pennsylvania & 29.66 \\
\hline South Carolina & 41.48 \\
\hline South Dakota & 38.24 \\
\hline Tennessee & 41.12 \\
\hline Texas & 47.12 \\
\hline Utah & 45.92 \\
\hline Vermont & 30.27 \\
\hline Virginia & 34.11 \\
\hline Washington & 45.16 \\
\hline West Virginia & 38.44 \\
\hline Wisconsin & 35.34 \\
\hline Wyoming & 50.32 \\
\hline
\end{tabular}

*There is no available rural data for Rhode Island, New Jersey and District of Columbia 


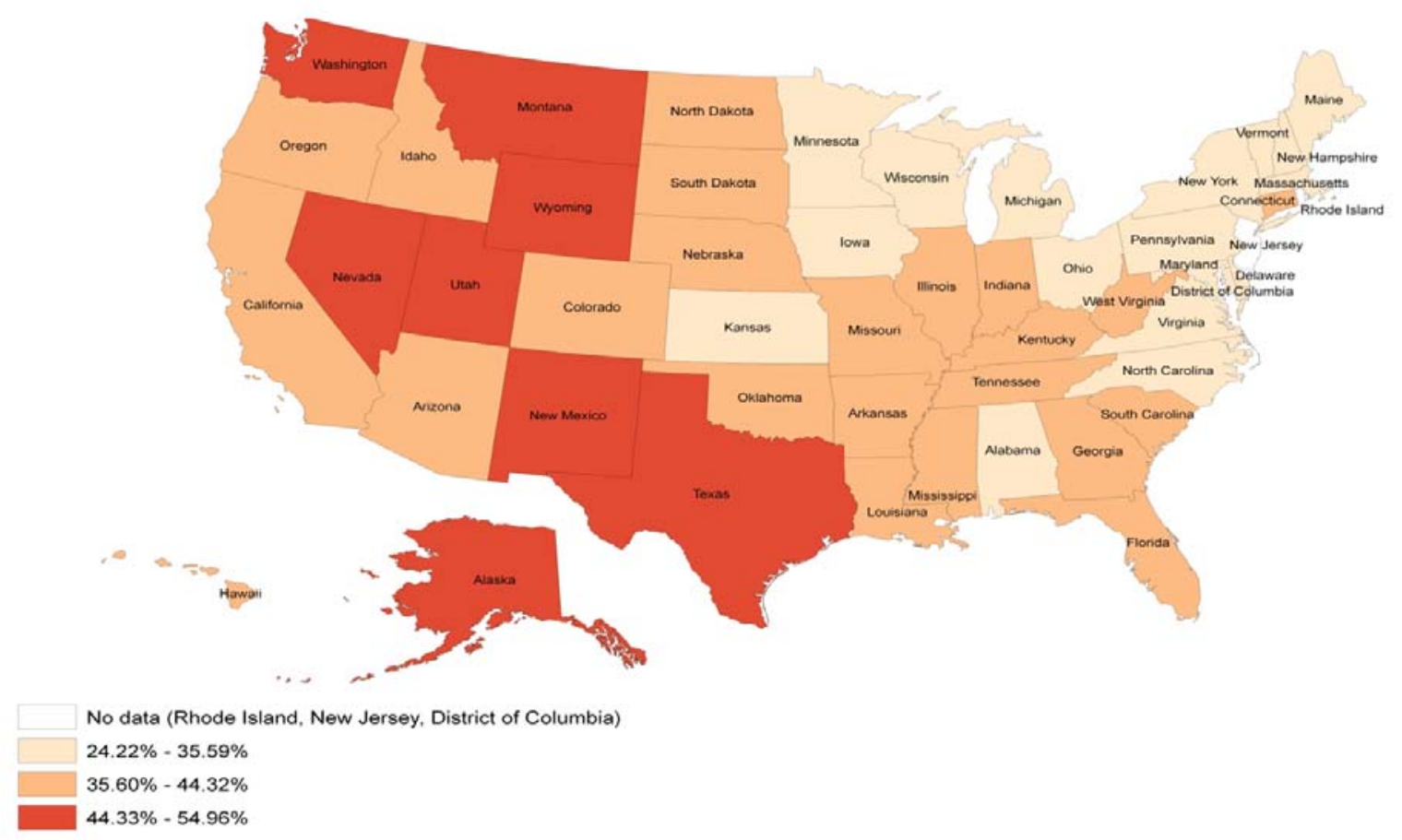

Figure 1. Percentage Tertiles of U.S. Rural Adults $>45$ Years of Age With Self-Reported Arthritis Diagnosis and At Least One Health Service Deficit 2011 BRFSS Data

The most significant finding was that after controlling for factors such as SES and race/ethnicity, rural adults age 45 years or older with arthritis were about $14 \%$ more likely to experience a health service deficit than their urban counterparts. We believe this finding is important for several reasons. First, a critical initial step to addressing health care disparities is an appreciation of who may be at risk ${ }^{[28,29]}$ and who may not be accessing services. This notion is grounded in the understanding that societies shape patterns of disease and that these patterns change over time in response to multiple factors ${ }^{[30,31]}$. A growing body of literature indicates the complex social and economic interaction neighborhoods contribute to health disparities independent of individual-level risk factors ${ }^{[32]}$. While disparities in health and health care among minorities and those of low SES is a well-recognized problem, rural health disparities is becoming more recognized $^{[11,33,34]}$ and suggests that rural culture may be a health determinant ${ }^{[11,35]}$. Our findings add to this growing body of knowledge establishing rural residency as a risk factor and heightens an appreciation of the need to develop strategies that incorporate geography into programs that target the management of a chronic disease such as arthritis.

Understanding health service deficits is also important because it provides an indication how many individuals may not be receiving care. This study found that overall about 1 in 3 individuals suffering from arthritis experienced a health deficit. Given the burden of disease from arthritis this suggests that there is substantial potential for improving services and perhaps outcomes for individuals with arthritis. The two most common health service deficits were not having a routine medical checkup within the last 12 months and deferring needed health care because of cost. Having to delay seeking care because of cost likely affects not having seen a provider within the last 12 months and suggest that finances rather than simply the availability of services is a stronger contributor for seeking care.

Similar to other studies ${ }^{[36]}$ we found that rural adults were more likely to report having arthritis. This difference may be explained, in part, by the fact that rural residents are more likely to be overweight or obese and older as compared to urban residents ${ }^{[11]}$. These two factors are also associated with OA development and progression. Moreover, farmers are at a significantly higher risk of developing OA as compared to other occupationally active men ${ }^{[37]}$. While the percent of rural 
residents who farm has decreased over the past few decades farming still represents a substantial portion of the rural workforce.

While there is no cure for OA, the most common type of arthritis, experiencing a health service deficit can contribute to more poorly managed disease. OA is linked to a poor quality of life ${ }^{[5]}$ and pain associated with suboptimal management likely impacts the quality of life for those with this type of arthritis. As noted in the introduction, there is a close interdependence between untreated pain and depressive symptoms, both of which can contribute to poor quality of life and disability ${ }^{[20-23]}$. Planned care that optimizes quality of life, prevents progression of the disease, manages acute flare-ups and judiciously manages coexisting conditions can benefit individuals with $\mathrm{OA}^{[38]}$.

Since rural residents are at greater risk for arthritis, policies targeted toward these individuals might be beneficial. In addition to providing better access to clinicians, programs that improve rural residents' access to nutrition counseling, structured exercise programs, such as aquatic therapy, and health care providers such as occupational therapists and physiotherapists, might prove beneficial. Also, the rural built environment may not be as accommodating as the urban built environment to those individuals with arthritis who could benefit from physical activity an accommodating built environment might provide.

\section{Limitations}

Several potential limitations to this study should be noted. First, the survey is based on telephone interview derived data and may be skewed because those who could not be reached by phone could not participate in the survey. For example, the wide-spread use of answering machines and caller ID allow people to filter their telephone calls potentially leading to a passive refusal to participate in health surveillance surveys such as the BRFSS. However, the use of answering machines and caller ID to filter out "unwanted" or "unfamiliar" callers is beyond the control of survey administrators. In addition, some persons of lower SES may have been excluded because of lack of telephone access, but the fact that the vast majority of U.S. residents live in households with telephones minimizes this bias. Furthermore, U.S. cell phone numbers are now included in the pool of phones contacted for the survey.

A second limitation is that the survey used close-ended questions, which limit responder's options to fully explain response choices. However, the survey questions were worded such that the answer choices covered a wide range of response possibilities. A third and related limitation is that the answers are self-reported, which introduces the possibility of exposure and outcome misclassification on the part of the survey participants.

A fourth limitation is that only those variables available from the survey questions could be used and these questions may not reflect a fully comprehensive measure of the concept health service deficits. Finally, this study analyzed crosssectional data, limiting assessment of causal relationships. At best associations are detectable in cross-sectional studies such as the one presented here. Furthermore, at this point we are uncertain as to whether identified associations are differential with respect to individual health service deficits or number of health service deficits. Further analysis will examine those associations.

\section{Conclusions}

Understanding health service deficits is important because it provides an indication how many individuals may not be receiving care. Rural geographic residency was an independent predictor for a higher prevalence of health service deficits for U.S. adults $>45$ years of age with arthritis. Furthermore, having to delay seeking care because of cost affects not having seen a provider within the last 12 months and suggests that finances rather than simply the availability of services is a strong contributor for seeking care. Given the burden of disease from arthritis the results suggest that there is 
considerable potential for improving services and perhaps improving outcomes for individuals with arthritis, especially those from rural settings.

\section{Acknowledgement}

This research was sponsored by the Rural Scientific Interest Group (Rural SIG) of the HMO Research Network (HMORN). HMORN is a consortium of health care delivery organizations with both defined patient populations and formal research capabilities. The mission of HMORN is to use collective scientific capabilities to integrate research and practice in order to improve health and health care among diverse populations. The Rural SIG seeks to facilitate collaborative research addressing the health and health care of U.S. rural populations.

\section{References}

[1] Hunter DJ, Eckstein F. Exercise and osteoarthritis. J Anat. 2009; 214: 197-207. PMid:19207981

http://dx.doi.org/10.1111/j.1469-7580.2008.01013.x

[2] Helmick CG, Felson DT, Lawrence RC, Gabriel S, Hirsch R, Kwoh CK, Liang MH, Kremers HM, Mayes MD, Merkel PA, Pillemer SR, Reveille JD, Stone JH. National Arthritis Data Workgroup. Estimates of the prevalence of arthritis and other rheumatic conditions in the United States. Part I. Arthritis Rheum. 2008; 58: 15-25. PMid:18163481 http://dx.doi.org/10.1002/art.23177

[3] Bedson J, Mottram S, Thomas E, Peat G. Knee pain and osteoarthritis in the general population: what influences patients to consult? Fam Pract. 2007; 24: 443-53. PMid:17675657 http://dx.doi.org/10.1093/fampra/cmm036

[4] Weigl M, Cieza A, Cantista P, Reinhardt JD, Stucki G. Determinants of disability in chronic musculoskeletal health conditions: a literature review. Eur J Phys Rehabil Med. 2008; 44: 67-79. PMid:18385630

[5] Tarride JE, Haq M, O'Reilly DJ, Bowen JM, Xie F, Dolovich L, Goeree R. The excess burden of osteoarthritis in the province of Ontario, Canada. Arthritis Rheum. 2012; 64: 1153-1161. PMid:22081470 http://dx.doi.org/10.1002/art.33467

[6] Theis KA, Murphy L, Hootman JM, Helmick CG, Yelin E. Prevalence and correlates of arthritis-attributable work limitation in the US population among persons ages 18-64: 2002 National Health Interview Survey Data. Arthritis Rheum. 2007; 57: $355-363$. PMid:17394215 http://dx.doi.org/10.1002/art.22622

[7] Krasnokutsky S, Samuels J, Abramson SB. Osteoarthritis in 2007. Bull NYU Hosp Jt Dis. 2007; 65: 222-228. PMid:17922674

[8] Pearson-Ceol J. Literature review on the effects of obesity on knee osteoarthritis. Orthop Nurs. 2007; 26: 289-292. PMid:17921888 http://dx.doi.org/10.1097/01.NOR.0000295955.63956.1d

[9] Lutfiyya MN, McCullough JE, Lipsky MS. A population-based study of health service deficits for US adults with asthma. J Asthma. 2011; 48: 931-944.

[10] Lutfiyya MN, Haller IV. Introduction: Place Matters. Dis Mon. 2012; 58: 618-619. http://dx.doi.org/10.1016/j.disamonth.2012.08.002

[11] Lutfiyya MN, McCullough JE, Haller IV, Waring SC, Bianco JA, Lipsky MS. Rurality as a root or fundamental social determinant of health. Dis Mon. 2012; 58: 620-628. PMid:23062678 http://dx.doi.org/10.1016/j.disamonth.2012.08.005

[12] Agency for Healthcare Research and Quality. National healthcare disparities report. National Center for Health Statistics. 2007. Available from: http://www.ahrq.gov/htm. PMid:23062678

[13] Graves BA. Telehealth for communities: toward eliminating rural health disparities. Online J Rural Nursing Health Care. 2010 ; 10.

[14] Doescher MP, Jackson JE, Jerant A, Hart LG. Prevalence and Trends in Smoking: A National Rural Study. J Rural Health. 2006; 2: 112-118. PMid:16606421 http://dx.doi.org/10.1111/j.1748-0361.2006.00018.x

[15] Danaei G, Rimm EB, Oza S, Kulkarni SC, Murray CJL, Ezzati M. The Promise of Prevention: The Effects of Four Preventable Risk Factors on National Life Expectancy and Life Expectancy Disparities by Race and County in the United States. PLoS Medicine. 2010; 7.

[16] Vander Weg MW, Cunningham CL, Howren MB, Cai X. Tobacco use and exposure in rural areas: Findings from the Behavioral Risk Factor Surveillance System. Addict Behav. 2011; 36: 231-236. PMid:21146318 http://dx.doi.org/10.1016/j.addbeh.2010.11.005

[17] Lutfiyya MN, Shah KK, Johnson M, Bales RW, Cha I, McGrath C, Serpa L, Lipsky MS. Adolescent daily cigarette smoking: is rural residency a risk factor? Rural Remote Health. 2008; 8: 875. PMid:18366278

[18] Krishna S, Gillespie KN, McBride TM: Diabetes burden and access to preventive care in the rural United States. J Rural Health. 2010; 26: 3-11. PMid:20105262 http://dx.doi.org/10.1111/j.1748-0361.2009.00259.x 
[19] Lutfiyya MN, Chang LF, Lipsky MS. A cross-sectional study of US rural adults' consumption of fruits and vegetables: do they consume at least five servings daily? BMC Public Health. 2012; 12: 280. PMid:22490063 http://dx.doi.org/10.1186/1471-2458-12-280

[20] Anderson KO, Bradley LA, Young LD, McDaniel LK, Wise CM. Rheumatoid arthritis: review of psychological factors related to etiology, effects, and treatment. Psychological Bulletin. 1985; 98: 358-387. PMid:3901066 http://dx.doi.org/10.1037/0033-2909.98.2.358

[21] Bayat N, Alishiri GH, Salimzadeh A, Izadi M, Saleh DK, Lankarani MM, Assari S. Symptoms of anxiety and depression: a comparison among patients with different chronic conditions. J Res Med Sci. 2011; 16: 1441-1447. PMid:22973345

[22] Lutfiyya MN, Bianco JA, Quinlan SK, Hall C, Waring SC. Mental health and mental health care in rural America: the hope of redesigned primary care. Dis Mon. 2012; 58: 629-38. PMid:23062679 http://dx.doi.org/10.1016/j.disamonth.2012.08.004

[23] Wilkie R, Blagojevic M, Jordan KP, Lacey R, McBeth J. Reasons why multimorbidity increases the risk of participation restriction in older adults with lower limb osteoarthritis: a prospective cohort study in primary care. Arthritis Care Res. 2012. doi: 10.1002/acr.21918. http://dx.doi.org/10.1002/acr.21918

[24] Mokdad AH, Stroup DF, Giles, WH. Public health surveillance for behavioral risk factors in a changing environment: recommendations from the Behavioral Risk Factor Surveillance Team. Morbidity and Mortality Weekly Report 52. 2003 ; RR09.

[25] Musgrove P, Creese A, Preker A, Baeza C, Anell A, Prentice T. Health Systems: Improving Performance. WHO. France: 2000.

[26] American Psychological Association, Task Force on Socioeconomic Status. Report of the APA Task Force on Socioeconomic Status. Washington, DC: American Psychological Association, 2007.

[27] Department of Defense. Population Representation in the Military Services: Fiscal Year 1999. Washington, DC: Office of the Assistant Secretary of Defense, Force Management and Personnel, 2000.

[28] Woolfolk, A. Educational psychology (10th ed.). Boston: Allyn and Bacon, 2007.

[29] Smedley BD, Smith AY, Nelson AR. Unequal treatment confronting racial and ethnic disparities in healthcare. Washington DC: The National Academy Press, 2003.

[30] Phelan JC, Linkl BG, Tehranifar P. Social Conditions as Fundamental Causes of Health Inequalities: Theory, Evidence, and Policy Implications. J Health Soc Behav. 2010; 51: 28-40. PMid:20943581 http://dx.doi.org/10.1177/0022146510383498

[31] Link BG, Phelan JC. Editorial: Understanding Sociodemographic Differences in Health--The Role of Fundamental Social Causes. Am J Public Health. 1996; 86: 471-472. PMid:8604773 http://dx.doi.org/10.2105/AJPH.86.4.471

[32] Pearlman DN, Zierler S, Meersman S, Kim HK, Viner-Brown SI, Caron C. Race disparities in childhood asthma: does where you live matter? J Natl Med Assoc. 2006; 98: 239-247. PMid:16708510

[33] Lutfiyya MN, Patel Y, Steele J, Tetteh B, Chang L, Aguero C, Prakash O, Lipsky MS. Are there disparities in diabetes care? A comparison of care received by U.S. rural and urban adults with diabetes. J Prim Care Res Develop. 2009; 9: $320-331$. http://dx.doi.org/10.1017/S146342360999017X

[34] Lutfiyya MN, Lipsky MS, Wisdon-Behonek J, Inpanbutr-Martinkus M. Is rural residency a risk factor for overweight or obese U.S. children? Examination of national survey data. Obesity. 2007; 15: 2348-2356. PMid:17890504 http://dx.doi.org/10.1038/oby.2007.278

[35] Hartley D. Rural health disparities, population health, and rural culture. Am J Public Health. 2004; 94: 1675-1678. PMid:15451729 http://dx.doi.org/10.2105/AJPH.94.10.1675

[36] Enyinnaya EI, Anderson JG, Merwin EI, Taylor AG. Chiropractic use, health care expenditures, and health outcomes for rural and nonrural individuals with arthritis. J Manipulative Physiol Ther. 2012; 35: 515-524. Epub 2012 Aug 27. PMid:22951269 http://dx.doi.org/10.1016/j.jmpt.2012.07.010

[37] Thelin A, Holmberg S. Hip osteoarthritis in a rural male population: A prospective population-based register study. Am J Ind Med. 2007; 50: 604-607. PMid:17597473 http://dx.doi.org/10.1002/ajim.20484

[38] McKenzie S, Torkington A. Osteoarthritis - management options in general practice. Aust Fam Physician. 2010; $39: 622-625$. PMid:20877763 